\title{
LASER SCANNING FOR THE GEOMETRIC STUDY OF THE ALCÁNTARA BRIDGE AND CORIA CATHEDRAL
}

\author{
J. De Matías ${ }^{\mathrm{a}, *}$, F. Berenguer ${ }^{\mathrm{b}}$, J.P. Cortés ${ }^{\mathrm{c}}$, J.J. De Sanjosé ${ }^{\mathrm{a}}$, A. Atkinson ${ }^{\mathrm{a}}$ \\ a Escuela Politécnica, Universidad de Extremadura, Cáceres, Spain - (jmatias, jjblasco, atkinson)@unex.es \\ b Escuela Politécnica, Universidad de Extremadura, Cáceres, Spain - ferbese1@gmail.com \\ c INGECOES - jpcortes@ingecoes.es \\ Commission V, WG V/4
}

KEY WORDS: Modelling, Arquitecture, TLS, Cultural heritage, Structure.

\begin{abstract}
:
The conservation of built heritage is becoming increasingly important, and may even be an obligation for future generations. Techniques must therefore be developed to help document heritage and thus improve knowledge and conservation.

The terrestrial laser scanning technique allows a massive capture of points of an object. Among its main applications are to obtain geometries of historic buildings and monuments, allowing the documentation of their heritage. But this technique also facilitates other very important information for the conservation of the monument in question from the same data set: the damage it presents.

We can, therefore, also document the geometry of the object by making a survey of the damage it presents at the moment of data collection. The cracks and their layout and trajectory can be observed, allowing measurements to be made to assess necessary conservation measures.

Given that the apertures of the same crack at different points in historical structures often vary by several centimeters, it is also important to know the extent of the damage along its entire path, and whether there is any relative motion between the two sides of the crack.

This communication presents the application of laser scanning in the Alcántara Bridge and Coria Cathedral, both in the province of Cáceres (Spain). It outlines the criteria used for scanning both monuments: selection of placements, recording technique, errors between placements and the elimination of residual points.

Once the mesh had been obtained, the information on the damage presented by these monuments was analysed, describing, characterizing and contrasting them with data taken in the field.
\end{abstract}

\footnotetext{
* Corresponding author. This is useful to know for communication with the appropriate person in cases with more than one author.
} 


\section{INTRODUCTION}

When speaking of historical buildings we tend to think of cathedrals, churches, palaces, etc. rather than the structural elements they consist of, the walls and pillars. Vaults and domes cover the spaces between walls and also on occasions structural elements such as flying buttress. But we also find ourselves faced with infrastructures such as bridges, aqueducts, etc.

It is undeniable that the work of conservation and maintenance of built heritage is increasingly necessary, not only for economic reasons but also because some of these infrastructures, in addition to providing a service to society, form part of our cultural heritage.

This paper presents the articles published on the Alcántara bridge (Cáceres), which was built across the river Tajo by Cayo Julio Lácer between 103 and 106 A.D. The bridge, triumphal arch and temple were declared a National Monument (Spain) on 13th August 1924. An application has been made to UNESCO for the declaration of the site as a World Heritage Site (Blanco, 1977).

The importance of Alcántara bridge as one of the largest bridges built by Roman engineering is very well known. Some of the geometric characteristics that make it so imposing are the fact that the $7.80 \mathrm{~m}$ width of the pillars is the widest in the Iberian Peninsula, the height of the road over the river is around $47 \mathrm{~m}$, the largest of its arches spans $28.80 \mathrm{~m}$, which is the widest in the Iberian Peninsula, in turn resulting in a ratio of 0.25 in relation to the width of its pillars and it is almost 150m long (Durán, 2004).

The construction of Coria Cathedral (Cáceres) began in the XVI century and has undergone a multitude of events, the worse of which took place on 1st November 1755 when the tower and some of the collapsed vaults. In 1931 it was declared a National Monument (Spain) (García, 1999).

It is composed of a single hall with a total length of $56 \mathrm{~m}$. It has five ornamented vaults with a radius of around $18 \mathrm{~m}$ and a height to its highest point of $22.5 \mathrm{~m}$. Apse vaults reaches a height of $23.5 \mathrm{~m}$. Transept vault is the only vault from original construction, the remainders having been reconstructed.

\section{DESCRIPTION OF GEOMETRY AND HERITAGE DAMAGE}

The Terrestrial Laser Scanning technique provides a massive collection of the points of an object. Among its main applications are to obtain the geometries of historical buildings and monuments, which facilitates the documentation of their heritage. But in the same data collection we can also obtain information valuable to the conservation of the monument in question regarding damages (Lourenco et al., 2010), (Salonia et al., 2007).

We examine in detail the cracks, deformations and collapses that the constructions of our heritage have undergone by subjecting them to laser scan analysis.

To this end, in order to take decisions from the point of view of conservation and maintenance, the pathologies of the monument must be diagnosed, and in order to make a damage catalog. Therefore, in addition to the geometric documentation of the monument, the damage at the moment of collecting the data must also be documented, including structure, cracks, deformations and collapses,...

The aim of this paper is to apply laser scanning as an instrument for the inventory of damages to historical structures.

\section{GEOMETRIC INVENTORY OF THE ALCÁNTARA BRIDGE}

The pieces of equipment used were the Faro Laser Scanner LS 840 and the Leica Scanstation C10 (Trancón, 2011).

The preparatory phase prior to placing the equipment requires the decision of the recording technique to use. For this project scanning through scanned target resection was adopted given the large size of the Alcántara bridge, and a minimum of 12 placements were needed to make the complete scan.

The choice of the placement of the targets was made such that each placement collected a minimum of 3 targets in scanning area.

The data obtained were imported from the internal disk of the Leica Scanstation C10 to the Cyclone 7.1 program, converting the data from BIN to XYZ format. This program has a diana recognition tool that gives a geo-referenced cloud of points. A cloud of 120 million points was obtained, and these data were treated using Trimble Realworks 6.5.

In order to check for any possible movements in one placement with respect to another during the cloud-based recording, the coordinates of topographical points obtained in the triumphal arch were compared with the same points in other placements and with the correspondence of each point observed within the same local system of coordinates of the program (Table 1).

\begin{tabular}{|c|c|c|}
\hline \multicolumn{2}{|l|}{ Laser point 1} & Topographic point 1 \\
\hline Coordinates: & $12.57 \mathrm{~m} ; 95.66 \mathrm{~m} ; 10.63 \mathrm{~m}$ & Coordinates: $\quad 12.56 \mathrm{~m} ; 95.66 \mathrm{~m} ; 10.63 \mathrm{~m}$ \\
\hline Laser point 2 & & Topographic point 2 \\
\hline Coordinates: & 12.53 m; 95.64 m; 9.17 m & Coordinates: $\quad 12.52 \mathrm{~m} ; 95.65 \mathrm{~m} ; 9.17 \mathrm{~m}$ \\
\hline Laser point 3 & & Topographic point 3 \\
\hline Coordinates: & $24.33 \mathrm{~m} ; 93.26 \mathrm{~m} ; 10.57 \mathrm{~m}$ & Coordinates: $\quad 24.35 \mathrm{~m} ; 93.24 \mathrm{~m} ; 10.57 \mathrm{~m}$ \\
\hline Laser point 4 & & Topographic point 4 \\
\hline Coordinates: & $25.06 \mathrm{~m} ; 96.46 \mathrm{~m} ; 10.54 \mathrm{~m}$ & Coordinates: $\quad 25.05 \mathrm{~m} ; 96.48 \mathrm{~m} ; 10.54 \mathrm{~m}$ \\
\hline
\end{tabular}

Table 1. Comparison of laser and topographic points.

There was an error of less than $2 \mathrm{~cm}$, which is acceptable for the use of the recording based on clouds and targets in the network of Roman monuments at Alcántara.

From the correctly recorded and geo-referenced clouds the residual points (noise) were eliminated, such as vegetation, urban features, areas of natural land, etc. The number of points was significantly reduced, and the speed and capacity of processing was increased.

The meshing process was continued until the geometry of the bridge was obtained, its sections, elevations, etc.

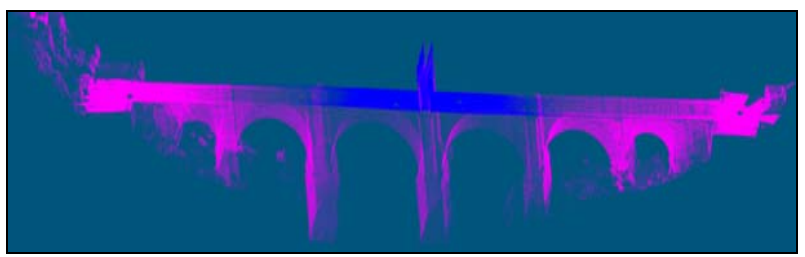

Figure 1. Final cloud of points.

Once all the scans had been put together, the 3D model of the bridge was made using Trimble Realworks v6.5 (Figure 1), and longitudinal (Figure 2), horizontal (Figure 3) and transversal sections (Figure 4) of the bridge were obtained.

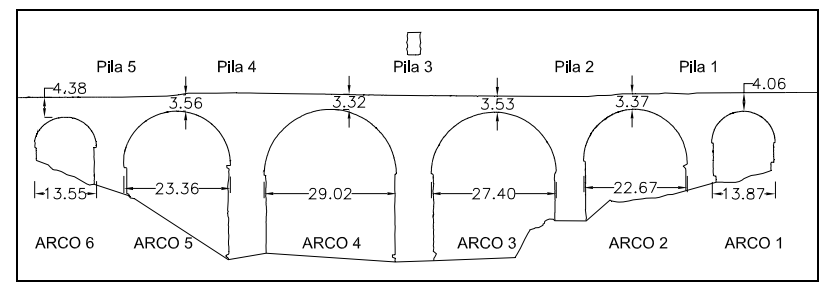

Figure 2. Longitudinal section of the bridge of Alcántara. 


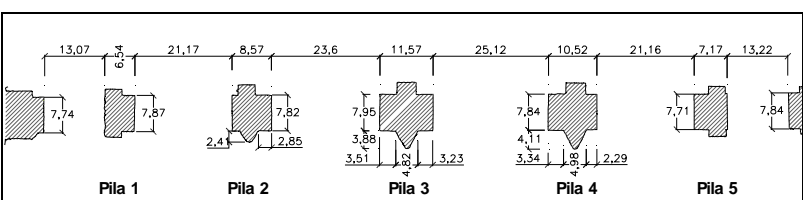

Figure 3. Horizontal sections of the pillars above the start of the arches.

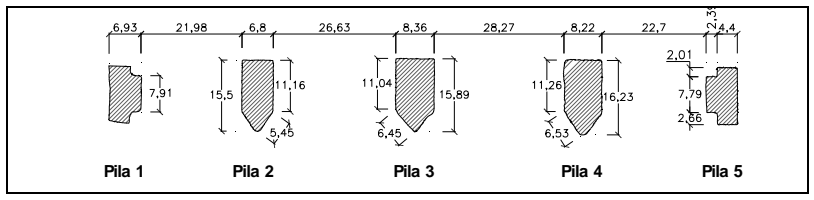

Figure 4. Horizontal sections of the pillars below the start of the arches.

\section{ANALYSIS OF THE RESULTS OF THE ALCÁNTARA BRIDGE}

The suitable conservation of a historic construction requires its correct documentation and geometry. The bridge of Alcántara is a paradigm in this sense, as the geometric definition available gave very differente results, and moreover the data were not geo-referenced, which meant that any possible movements and displacements of the bridge could not be monitored (Fernández, 2001), (Rodríguez, 1992), (López, 2001), (Obras, 1857).

From the analysis of the geometry represented by laser scan, significant differences were found between the results obtained and the drawings and plans that already exist (Durán, 2004). For example, regarding the span of the arches, the differences are close to a meter in the case of arches 2 and 4 compared with the data of Taramas (s. XVII) (Blanco, 1977), and even greater than a meter in arch 4 when compared with those of $\mathrm{F}$. Rodríguez (Cruz, 2001), (Liz, 1988). But even in the case of the most recent measurements, such as those made by the Revista de Obras Públicas (R.O.P.) in 1926 (Obras, 1926), they reflect spans between arches from left to right $(13.20 \mathrm{~m}-22.00 \mathrm{~m}-$ $26.23 m$ - 28.00m - 22.69m - 12.63m) with considerable differences, with all spans less than those obtained using TLS of $80 \mathrm{~cm}$.

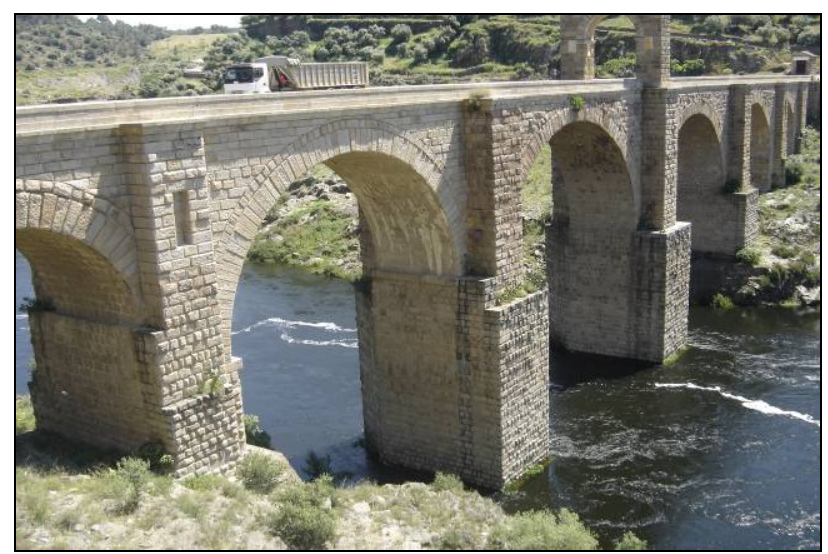

Figure 5. View of pile 4 under the triumphal arch.

In the case of the pillars these differences in measurements were also detected. In the central pile, the most important due to its dimensions and the role it plays in the formal composition of the bridge, we observe that the width assigned by F. Rodríguez is over $2 \mathrm{~m}$ less than measurements using TLS. The length is over a meter greater than that measured by TLS, as it measures the length of the rectangular part of $12.20 \mathrm{~m}$. Nevertheless, for this element the R.O.P. gives practically the same value for the width of the pile $8.30 \mathrm{~m}$, and for the total length of a mean somewhat higher, $16.60 \mathrm{~m}$ for the $15.90 \mathrm{~m}$ measured.

From the point of view of resistant behaviour the analysis of geometry showed that the most outstanding feature, taking into account that it is a 1900 year old structure, was that the arches present a very similar deformation to the theoretical deformation of an arch subjected to vertical loads. For example, in arch 4 (Figure 5), the one with a longest span, the maximum deviation between the real and the theoretical geometry of the circumference arch is less than $7 \mathrm{~cm}$. This shows the correct behaviour of the arches, as deformations due to assymmetrical thrusting, foundation movements or other anomalies were not observed.

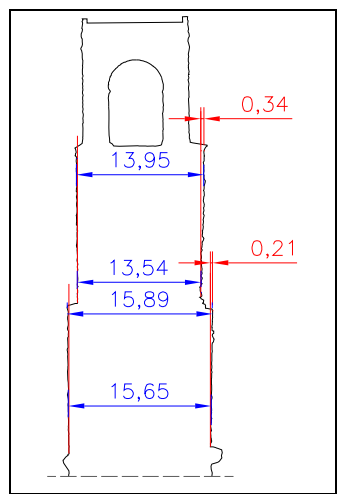

Figure 6. Transversal section of pile 4 (values in meters).

The upstream surfaces of pillars 4 and 5 present a slight collapse, which is greater in pile 4 . This collapse is $21 \mathrm{~cm}$ in the section from the cornice halfway up the pile and the beginning of the arch. In the section from the beginning of the arch to the impost (a line of ashlars), the collapse is $34 \mathrm{~cm}$ (Figure 6). This is coupled with the fact that the length of these pillars is not uniform throughout its height, but is greater in the upper part of each section. The downstream surface is practically vertical, and does not present any significant collapses.

\section{GEOMETRIC INVENTORY OF CORIA CATHEDRAL}

Different placements were proposed, some external to take in the northern side, which is the entrance to the cathedral, and the eastern side, which shows more damage to the façade and which will be used for the study of damages. Secondly, other internal scans were proposed, in which the internal part of the cathedral can be taken in, and lastly the roof, where coordinates obtained through total station were used to join the different scans (Morato, 2011)

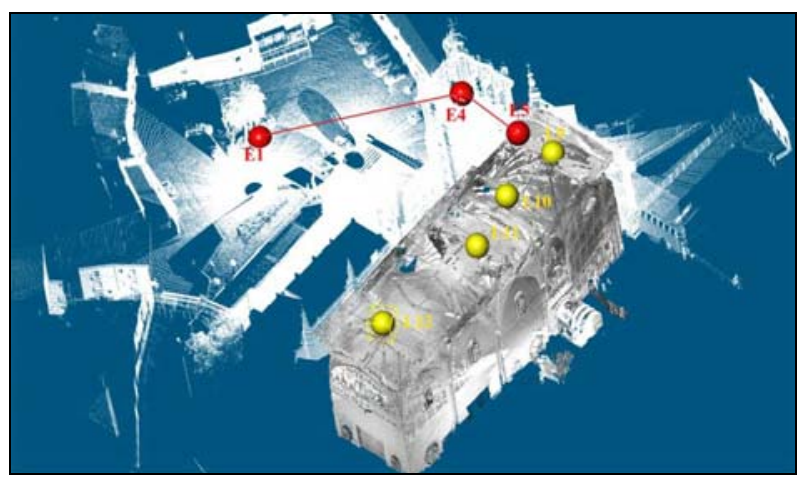

Figure 7. Scanning and station location. 
In the scan of the last part, the laser Faro laser Scanner LS 840 was used. The other scans were made using the laser scanner Leica Scanstation C10. The help of total station equipment was also necessary to place to know coordinates of over-vault.

The figure 7 shows the topographic stations to carry coordinates to the over-vault (E1, E4 and E5) and the scans made in the part of the over-vault (L9, L10, L11 and L12).

Once the corresponding scans had been taken, the cloud of points was made with the help of the software Faro Scout LT, and then the 3D model was constructed. Similarly, the same process was followed as with the scans made using the Leica Scanstation C10, with the difference that the Cyclone Navigator was used (Figure 8), in which the data obtained with the laser scanner were used.

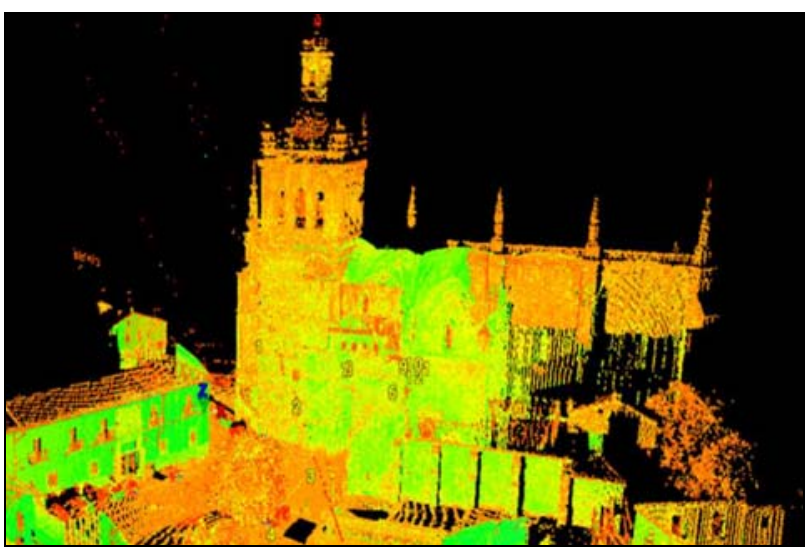

Figure 8. Cloud of points recorded with the Cyclone Navigator.

The errors obtained in each of the targets were checked in order to know whether they were correct. Recording is valid with at least three targets with an smaller error than $3 \mathrm{~cm}$. In our case none of these targets had to be discarded as the error was acceptable in all cases (Figure 10).

\begin{tabular}{|c|c|c|c|c|c|c|c|}
\hline de someres. & $=$ & conomativa & \multicolumn{5}{|l|}{ encostum | } \\
\hline$=710$ & Seconsote & $\operatorname{sen} w i d t$ & 7,000 & $2=$ & Wogt & & finverver \\
\hline & & $2=00003$ & & & & & $00000 \mathrm{~m}$ \\
\hline$=03$ & semolis. & senoces. & 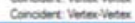 & on & 10000 & $6000=$ & 10001,00000000 \\
\hline $2=02$ & 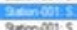 & 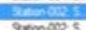 & 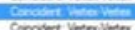 & का & Tw & $\log _{0}$ & 40 \\
\hline $\operatorname{ton}_{2}$ & & & Conotet ver vithe & on & $\underbrace{10000}_{0.000}$ & bosm- & 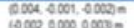 \\
\hline Tonse 2 & oxancots & $2 \tan 00$ is & conotent westuse & an & 1000 & $0005=$ & 00020000000 \\
\hline Tyme 2 & & & conosent it & a & 10000 & $00002=1$ & m. \\
\hline 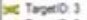 & & & conos & $\infty$ & 10000 & [00010 & $0001,0000,00001 \mathrm{~m}^{2}$ \\
\hline $\ln m=3$ & stancoes 5 & senoses. & Conobet vere vere & on & 10000 & 000in- & $0001.0000 .00001 \mathrm{~m}$ \\
\hline$=0,3$ & coms & & 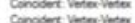 & $\infty$ & & 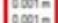 & $0000000000000 \mathrm{~m}$ \\
\hline$=\infty$ & 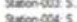 & sensens & 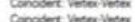 & $m$ & 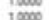 & (2) & - \\
\hline$=012$ & reonosets. & 2eonos: 5 & conotort vereviver & & 10000 & $0001=$ & 00000000000 \\
\hline
\end{tabular}

Figure 9. Error in the record through targets.

Using the program Trimble Realworks the points of the system of coordinates of the laser scanner itself were transformed to the local system performed using the total station. This conversion was carried out using the geo-referencing tool of the program Trimble Realworks such that by selecting the station the coordinates of the placements previously shown were given and thus the scans could be aligned. The mean error obtained using this method was $2 \mathrm{~cm}$, which was considered valid. (Figure 10).

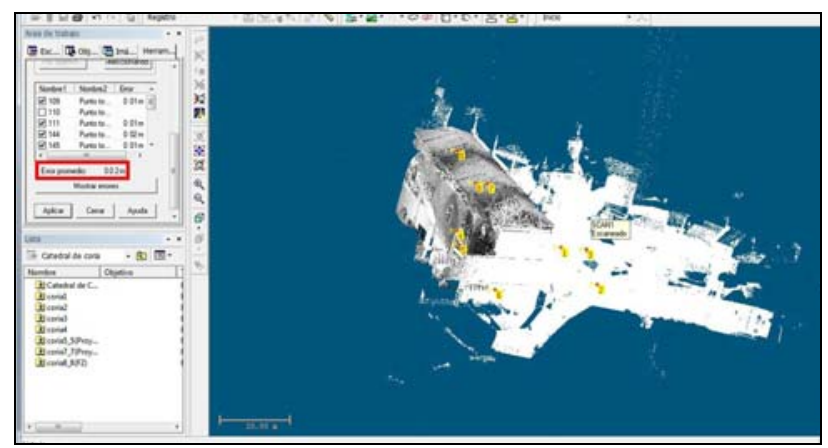

Figure 10. Mean error of geo-referencing.

Once a total cloud of points has been obtained, in which the sum of the different scans is available, it must be filtered to eliminate vegetation, urban objects, etc. to get the definitive cloud of points.

As the final process in 3D modelling, the mesh is obtained from the final cloud of points. The points of the cloud are joined together by triangulation and the resulting density of points is reduced. For the cathedral, these two sampling methods were used depending on the part to sample. In the area of the overvault random sampling was used about $60 \%$ of the time as it is a space with very little homogeneity.

For the rest of the cathedral, spatial sampling was used with one point every 3.5 and $5 \mathrm{~cm}$ for the interior and exterior respectively, as the spaces were homogeneous and so it was easier to sample these points and later to make the mesh.

From the 3D mesh modelling we obtain the sections and data necessary for the geometric and damage analyses described below.

\section{ANALYSIS OF THE RESULTS OF CORIA CATHEDRAL}

By means of the laser scanner technique we obtained the real geometry of the cathedral. The analysis of this deformed geometry provides information for the interpretation of the existing damages.

The collapses of the walls have been measured (horizontal displacements of the upper part with respect to the lower). The most significant movements have taken place in the southern wall, which presents an outward collapse that varies between $17 \mathrm{~cm}$ in vault 3 and $50 \mathrm{~cm}$ in vault 4 (figure 11), whereas the northern wall remains practically vertical.

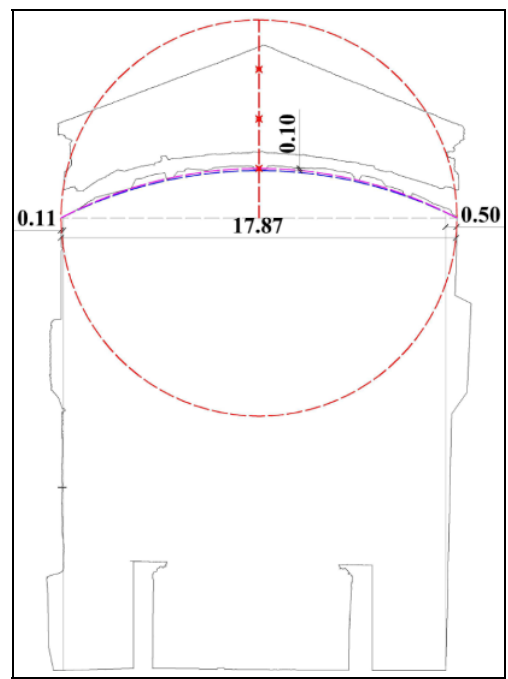

Figure 11. Measurements of collapses in vault 4 (values in meters)

These displacements are in accordance with the wide vertical cracks in the walls of the eastern façade. In the case of the vaults and arches, the comparison between the theoretical and the real geometry provide information on its behaviour. Thus, for example, in the traverse arch of vault 2 (figure 12), the area of the middle in the arch of the southern side, the deformation is displaced towards the exterior of the theoretical geometry by $14 \mathrm{~cm}$. On the northern side this displacement is $19 \mathrm{~cm}$, but towards the interior. This indicates that the vault behaves assymmetrically, with greater thrust towards the southern side, which is the wall with collapses. 


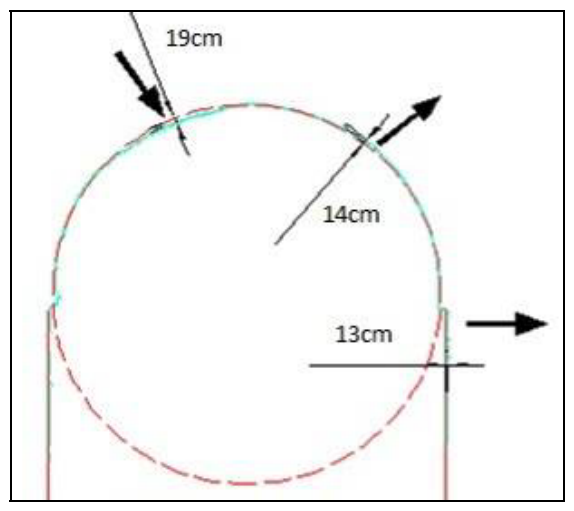

Figure 12. Displacements of vault 2.

In addition to data relative to the deformed geometry of the structure, data were also obtained on the cracks in the monuments, the trajectory of these cracks and their size. For example, figure 13 shows the façade of the eastern side, which is the one with the most damage, and the laser scanner measurements of the width of the cracks in this facade.

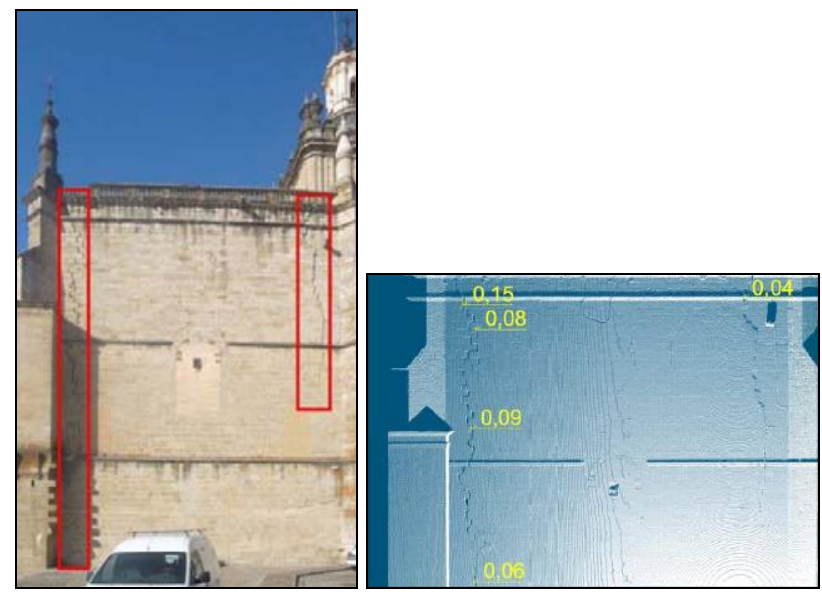

Figure 13. Eastern facade and inventory of cracks (values in meters).

The southern facade presents cracks with an arch shape, denoting settling of the land in this area.

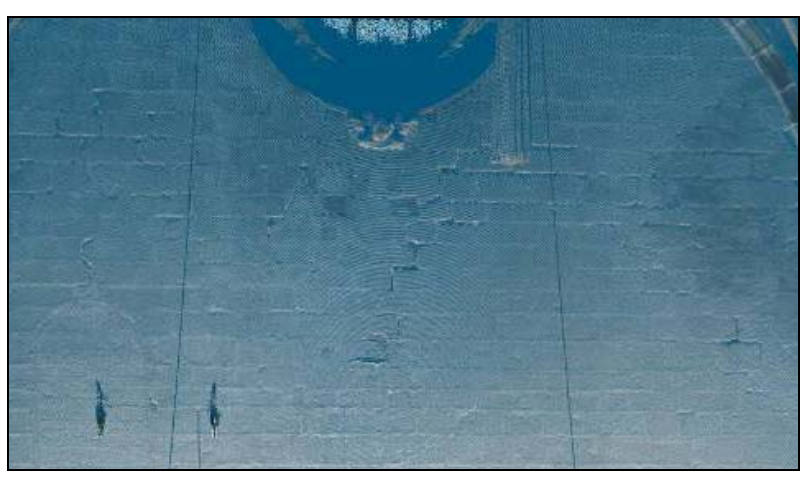

Figure 14. Track of the cracks in the eastern wall.

Using the laser scanner technique the real trajectories of the cracks (figure 14) as well as their widths were obtained.

Moreover, these displacements and cracks were related to those of the eastern façade and to the displacements in the vaults, allowing the analysis of the overall behaviour of the structure. In this way, this data collection has enabled us to follow the evolution of these cracks to know the area that is settling and the displacements that both the wall and the vaults are suffering.

\section{RESULTS AND CONCLUSIONS}

The results obtained were the geometric cataloguing of Alcántara bridge and Coria Cathedral for their documentation and improved knowlegde of these historical constructions. Furthermore, an inventory was made of the damage these structures now present, which will undoubtedly lead to an improvement in their conservation.

As we mentioned at the beginning of this article, the aim of this project was to analyse the possibility of using laser scanning both as a tool for the geometric definition of objects and to diagnose historical structures.

The execution of this project confirms the viability of the analysis of this kind of structure using laser scanning. Therefore, we can consider laser scanning as a technique for the diagnosis of historical structures, provided it is used by specialist technicians.

This technique is particularly useful in cases such as the one in this paper, either due to the difficulty of access (Alcántara bridge) or due to the complexity of the structure and its displacements (Coria cathedral).

\section{REFERENCES}

Blanco, A., 1977. El puente de Alcántara en su contexto histórico. Discurso de ingreso en la Real Academia de la Historia.

Cruz, M., 2001. El puente de Alcántara en los siglos XVII y XVIII. Noticias sobre su estado y planteamiento de restauración.

Durán, M., 2004. Técnica y construcción de puentes romanos. II Congreso de Obras Públicas Romanas, Tarragona.

Fernández, L., 2001. Intervenciones en los puentes de piedra”. Revista Ingeniería y Territorio.

García, F., 1999. La Catedral de Coria. Ed. Edilesa.

Liz, J., 1988. El puente de Alcántara: Arqueología e historia. Editorial MOPU, Centro de Publicaciones.

López, M., 2001. Criterios de actuación en la reparación del puente de Alcántara: respeto y economía. El informe del ingeniero Pelilla (1984). Revista Ingeniería y Territorio.

Lourenco, P.B., Peña, F., Amado, M., 2010. A document management system for the Conservation of Cultural Heritage Buildings. International Journal of Architectural Heritage, 1.

Morato, G., 2011. Estudio geométrico y análisis estructural de la Catedral de Coria. Proyecto Final de Carrera, Escuela Politécnica de Cáceres.

Revista de Obras Públicas, 1857. Tomo I, 1.

Revista de Obras Públicas, 1926. Tomo I, 3.

Rodríguez, C., 1992. El puente de Alcántara: reconstrucción en el siglo XIX, Cáceres. Institución Cultural El Brocense.

Salonia, P., Bellucci, V., Scolastico, S., Marcolongo, A., Leti, T., 2007. 3D Survey technologies for reconstruction, analysis and diagnosis in the conservation process of cultural heritage, 
in: Proceedings of XXI International CIPA Symposium, Athens, October 01-06.

Trancón, A., 2011. Estudio geométrico y análisis estructural del Puente de Alcántara. Proyecto Final de Carrera, Escuela Politécnica de Cáceres.

\section{ACKNOWLEDGEMENTS}

This work was funded by the Consejería de Economía, Comercio e Innovación of the Junta de Extremadura (Spain) through project: PRI09A025 and with FEDER funds. 